\title{
Associations of NSAID and paracetamol use with risk of primary liver cancer in the Clinical Practice Research Datalink
}

\author{
Baiyu Yang ${ }^{1}$, Jessica L. Petrick ${ }^{1}$, Jie Chen ${ }^{1}$, Katrina Wilcox Hagberg ${ }^{2}$, Vikrant V. \\ Sahasrabuddhe ${ }^{1,3}$, Barry I. Graubard ${ }^{1}$, Susan Jick ${ }^{2}$, and Katherine A. McGlynn' \\ ${ }^{1}$ Division of Cancer Epidemiology and Genetics, National Cancer Institute, Bethesda, MD, USA, \\ 20892-9774 \\ 2Boston Collaborative Drug Surveillance Program and Boston University School of Public Health, \\ Lexington, MA, USA, 02421 \\ ${ }^{3}$ Division of Cancer Prevention, National Cancer Institute, Bethesda, MD, USA, 20892-9783
}

\begin{abstract}
Liver cancer incidence has been rising rapidly in Western countries. Nonsteroidal antiinflammatory drugs (NSAIDs) and paracetamol are widely-used analgesics that may modulate the risk of liver cancer, but population-based evidence is limited. We conducted a case-control study (1195 primary liver cancer cases and 4640 matched controls) within the United Kingdom's Clinical Practice Research Datalink to examine the association between the use of prescription NSAIDs and paracetamol and development of liver cancer. Multivariable-adjusted odds ratios (aORs) and 95\% confidence intervals (CIs) were estimated using conditional logistic regression. Overall, ever-use of NSAIDs was not associated with risk of liver cancer $(\mathrm{aOR}=1.05,95 \% \mathrm{CI}=$ $0.88-1.24)$, regardless of recency and intensity of use. Use of paracetamol was associated with a slightly increased risk of liver cancer $(\mathrm{aOR}=1.18,95 \% \mathrm{CI}=1.00-1.39)$, particularly among individuals with body mass index $<25 \mathrm{~kg} / \mathrm{m}^{2}(\mathrm{aOR}=1.56,95 \% \mathrm{CI}=1.17-2.09)$. Our results suggest that NSAID use was not associated with liver cancer risk in this population. Ever-use of paracetamol may be associated with slightly higher liver cancer risk, but results should be interpreted cautiously due to methodological limitations. Given that paracetamol is a widely-used analgesic, further examination of its relationship with liver cancer is warranted.
\end{abstract}

\section{Keywords}

Analgesics; liver cancer; case-control study; medical records database

Correspondence to: Baiyu Yang, PhD, Division of Cancer Epidemiology and Genetics, National Cancer Institute, Bethesda, MD 20892-9774 (baiyu.yang@nih.gov). Work phone: 240-276-5319.

Conflict of Interest: None.

Publisher's Disclaimer: This is a PDF file of an unedited manuscript that has been accepted for publication. As a service to our customers we are providing this early version of the manuscript. The manuscript will undergo copyediting, typesetting, and review of the resulting proof before it is published in its final citable form. Please note that during the production process errors may be discovered which could affect the content, and all legal disclaimers that apply to the journal pertain. 


\section{INTRODUCTION}

Primary liver cancer is the second leading cause of cancer death worldwide [1]. Although it's relatively rare in the Western countries, its incidence has been rising rapidly in both the United Kingdom (UK) [2] and the United States (US) [3]. Furthermore, the effectiveness of surveillance and treatment of liver cancer is low [4], and the prognosis of liver cancer is poor [5]. Thus, it is of considerable clinical and public health importance to determine preventive strategies to reduce the disease burden of liver cancer.

Nonsteroidal anti-inflammatory drugs (NSAIDs) are widely-used medications with analgesic, antipyretic, and anti-inflammatory properties. As liver cancer develops on a background of chronic inflammation [6], NSAIDs may be chemopreventive against liver cancer based on their anti-inflammatory properties. Experimental studies have shown that NSAIDs may inhibit liver cancer cellular growth and induce cell apoptosis by modifying cyclooxygenase (COX) enzymatic pathways which mediate inflammation [7, 8]. Two reports from large observational studies suggested that NSAID use, specifically aspirin, was associated with reduced risk of liver cancer [9, 10], but NSAID use was self-reported in these studies. Associations between prescription NSAID use and liver cancer have not been previously described.

Paracetamol (acetaminophen) is another type of widely-used moderately-effective analgesic. Paracetamol overdose may induce hepatotoxicity and subsequent acute liver failure [11]. Patients with chronic liver disease may be especially susceptible to the adverse effects of paracetamol because of altered liver function [12]. We hypothesized that paracetamolinduced liver injury may predispose individuals to higher risk of liver cancer. Several animal studies have demonstrated the hepatocarcinogenicity of paracetamol [13], but evidence to evaluate the hepatocarcinogenicity in humans is scarce.

Thus, we examined the associations between prescription NSAID and paracetamol use and the development of liver cancer in the UK's Clinical Practice Research Datalink (CPRD), a large medical records database.

\section{MATERIALS AND METHODS}

\section{Data source}

This nested case-control study was conducted using data from CPRD, a large, populationbased, automated medical record database with information on approximately $8.5 \%$ of the UK population [14]. Diagnoses, physical findings, symptoms, and administrative events are recorded using Read codes [15], and the data are considered reasonably complete and accurate with regard to clinical illnesses diagnosed by the GP or a specialist $[16,17]$. Specifically, over $90 \%$ of information from manual medical records is recorded electronically $[16,17]$, and $95 \%$ of all electronically identified primary cancers were confirmed as incident cancer cases [18]. Detailed information for all prescribed medications is also available. This study was approved by the National Institutes of Health Human Research Protection Program and the Independent Scientific Advisory Committee of the CPRD (Protocol 12_127R2). 


\section{Study population}

As previously described [19], cases and controls were drawn from persons in the CPRD from 1988 through 2011 who were between the ages of 10 and 90 years. Cases met the following criteria: 1) first time diagnosis of primary liver cancer, 2) no code of liver metastases and no prior diagnosis of cancers most likely to have liver metastasis (lung, stomach, breast, colon, or pancreatic cancer), and 3) no diagnosis of any other cancer (except for nonmelanoma skin cancer) in the three years prior to the index date. The index date was defined as one year before the date of liver cancer diagnosis. All cases were required to have at least two years of history in the CPRD prior to the index date. Of the 1195 cases, 86.7\% had supporting clinical codes indicating presence of liver cancer, such as diagnostic exams, treatment, palliative care, and referrals to specialty care.

For each case, controls were selected from individuals who were in the CPRD at the case's index date and had no cancer diagnosis (except nonmelanoma skin cancer) prior to that date. Controls were matched to cases at a four-to-one ratio on age (year of birth), sex, general practice, and number of years in the CPRD prior to the case's index date. We then defined the controls' index date to be the same as the matched case's index date. Only three eligible controls could be identified for 59 of the cases, only two for 24 cases, and only one for 11 cases, resulting in a total of 4640 controls.

In addition to the full case-control match, we completed an additional match based on the presence of chronic liver disease. For the 170 cases with a history of chronic liver disease, 680 controls selected among individuals with liver disease in the CPRD were matched to these cases at a four-to-one ratio using the same matching factors as in the primary match. Similarly, the remaining 1025 cases without liver disease were matched to 4100 controls without chronic liver disease. This approach allows sufficient sample size for stratified analyses by chronic liver disease.

\section{Exposure definition}

Ever-use of NSAIDs was defined as having two or more NSAID prescriptions recorded prior to the index date of the individual, while non-use was defined as one or no NSAID prescriptions prior to the index date. The same definition was used for paracetamol use. Current use was defined as use that ended within one year prior to the index date, while past use was defined as use that ended more than one year prior to the index date. Total number of prescriptions was evaluated for ever users, and separately for current and past users. It was categorized as $2-9,10-19,20-39$, and $\geq 40$ prescriptions, written up to the index date. To assess the intensity of medication use, we calculated the time between first and last use of each medication (categorized as $<2$ years, $2-5$ years, and $>5$ years) and examined the association between total number of prescriptions and liver cancer risk within each time period category.

In addition to analyzing NSAID as a single entity, we also examined subtypes of NSAIDs individually, i.e., aspirin, COX-2 selective inhibitors, and other NSAIDs, using non-use of NSAIDs as the comparison group. 


\section{Statistical analysis}

We conducted conditional logistic regression to calculate the crude and adjusted odds ratio (cOR and aOR) and 95\% confidence interval (CI) for associations between NSAID and paracetamol use and liver cancer risk. In multivariable models, we adjusted for body mass index (BMI), smoking, alcohol-related disorders, hepatitis B virus (HBV) or hepatitis C virus (HCV) infection, diabetes, rare metabolic disorders, anti-diabetic medications, and statin use, selected a priori based on previous literature. In addition, models for NSAIDs were adjusted for paracetamol use, and models for paracetamol were adjusted for any NSAID use. For covariates with missing values, "unknown" categories were created for the analyses.

Four sensitivity analyses were conducted for both NSAID and paracetamol use, including 1) restricting the analysis to cases with clinical codes for liver cancer treatment (e.g., surgery, chemotherapy, or palliative care) and their matched controls; 2) using an index date of 2 years prior to the case's date of diagnosis, rather than 1 year; 3 ) restricting the analysis to participants without cardiac impairments; and 4) excluding participants under age 40. In addition, we conducted a sensitivity analysis to examine the use of 36 or more prescriptions of NSAIDs (overall and by subtype) vs. no use, because there is evidence that the effect of low dose aspirin use on the incidence of cancer does not start until after about 3 years of sustained use [20], and in the UK, 36 prescriptions would be equivalent to three years of use as NSAID prescriptions tend to be written for one month at a time. Furthermore, we tested for effect modifications by important covariates, including age at index date, sex, BMI and smoking status, using likelihood ratio tests. All analyses were performed using SAS version 9.3 (SAS Institute, Cary, NC, USA). All statistical tests were two-sided, and p values of less than 0.05 were considered statistically significant.

\section{RESULTS}

As shown in Table 1, the mean age of the study participants was 67 years, and $71.6 \%$ were men. Eligible liver cancer cases $(\mathrm{n}=1195)$ were more likely than matched controls $(\mathrm{n}=$ 4640) to be obese, to be current or former smokers, to be infected with HBV and/or HCV, and to have chronic liver disease, rare metabolic disorders, alcohol-related disorders, diabetes, hypertension, and congestive heart failure.

Table 2 shows the results of the analysis of NSAID use with liver cancer risk. There was no association between liver cancer risk and ever-use of NSAIDs after multivariable adjustment $(\mathrm{aOR}=1.05,95 \% \mathrm{CI}=0.88-1.24)$. The attenuation of $\mathrm{OR}$ in the multivariable model, compared to the crude model, was primarily driven by adjustment of history of diabetes, antidiabetic medication use, and paracetamol use. Similarly, there were no associations with liver cancer risk when NSAID use was stratified by the total number of prescriptions or the recency and intensity of use. Analyses of individual subtypes of NSAIDs and liver cancer risk also found no associations with one exception: ketoprofen use was associated with lower risk $(\mathrm{aOR}=0.27,95 \% \mathrm{CI}=0.07-0.99)$, although the CI was relatively wide (Table 3 ). As with the analyses of the whole dataset, analyses stratified on the presence of chronic liver disease also yielded no significant associations (Supplementary Table 1). 
Table 4 shows the association of paracetamol use with liver cancer risk. Ever-use of paracetamol was associated with a slightly increased risk of liver cancer $(\mathrm{aOR}=1.18,95 \%$ $\mathrm{CI}=1.00-1.39)$. This association was most evident for current use $(\mathrm{aOR}=1.30,95 \% \mathrm{CI}=$ 1.08-1.56) and long-term use (time between first and last prescription $>5$ years; aOR $=$ $1.26,95 \% \mathrm{CI}=1.03-1.54)$. The increased risk of liver cancer associated with paracetamol use was also observed among individuals without chronic liver disease, but not among those with chronic liver disease (Supplementary Table 2). We noted a statistically significant interaction between paracetamol use and BMI ( $p_{\text {interaction }}<0.01$ ), with increased risk observed only among those with $\mathrm{BMI}<25 \mathrm{~kg} / \mathrm{m}^{2}(\mathrm{aOR}=1.56,95 \% \mathrm{CI}=1.17-2.09)$ but not among those with BMI $\geq 25 \mathrm{~kg} / \mathrm{m}^{2}(\mathrm{aOR}=0.95,95 \% \mathrm{CI}=0.77-1.17)$ (Supplementary Table $3)$.

In sensitivity analyses, we observed no material deviation from the main results after restricting the analyses to cases with supporting clinical codes and their controls, restricting to participants without cardiac impairments, excluding participants under age 40 , or changing the index date to 2 years prior to date of diagnosis (results for paracetamol after changing the index date shown in Supplementary Table 4, other results not shown). In addition, when we evaluated sustained NSAID use in a sensitivity analysis, 36 or more prescriptions of NSAIDs were not associated with the risk of liver cancer (data not shown).

\section{DISCUSSION}

In the current study, we examined the association between NSAID and paracetamol use, as recorded in the CPRD's electronic clinical records, and risk of liver cancer. Overall, NSAID use was not associated with risk of liver cancer, although there was a suggestion of decreased risk associated with ketoprofen use. Paracetamol use was associated with a slightly increased risk of liver cancer, which was most evident in heavy and long-term users.

Previous US-based large cohort studies suggested that NSAID use, specifically aspirin, was associated with lower risk of hepatocellular carcinoma (HCC) $[9,10]$. In contrast, our study suggests a lack of association between NSAID use and liver cancer risk in the CPRD. An important difference between our study and the previous cohort studies is that NSAID use was obtained via prescription data in clinical records in our study, whereas the previous cohort studies used questionnaire-based information on self-reported past use of aspirin or other NSAIDs with only one time-point of exposure. Although using prescription data avoids any recall bias, an inherent limitation is missing information on over-the-counter (OTC) medication use. Notably, the proportion of participants with aspirin use is much lower in our study (28\% among controls) compared to cohort studies using self-reported NSAIDs (e.g., 73\% in the NIH-AARP study) [10]. Whether this difference reflects recall bias (and consequent overestimation of NSAID use) in the previous studies or missing OTC exposure in our study is unclear. However, there is no evidence of massive OTC purchase of NSAIDs in the UK especially in the older population. A validation study interviewed women in CPRD who had no records of prescription NSAIDs, and reported that $30 \%$ of them had OTC use of aspirin or ibuprofen, most of which were rare or occasional use [21]. Furthermore, a simulation study suggested that missing OTC drug exposure is not a large source of bias under realistic conditions of NSAID use; for example, assuming the true RR 
is 0.75 between NSAID use and a given outcome, with $70 \%$ of the population using NSAIDs and $30 \%$ of the NSAID use being OTC, the observed RR would be approximately 0.83 , slightly biased towards the null [22]. Thus, we believe that the discrepancy between our study results and those of previous cohort studies, which relied on self-reported NSAID use, may only be partially explained by missing OTC exposure in our study.

To our knowledge, the associations of paracetamol use with the risk of primary liver cancer have only been examined in one Danish cohort, and the authors observed higher liver cancer incidence among paracetamol users compared to expected incidence among those not receiving paracetamol prescriptions (standardized incidence ratio 1.5, 95\% CI 1.0-2.2) [24]. Similarly, in our study, we observed slightly higher risk of liver cancer with paracetamol use, particularly among those who had received many prescriptions for paracetamol, or those who received a moderate number of paracetamol over a short period of time. The mechanisms underlying this association may involve paracetamol-induced hepatotoxicity, following a complex sequence of events such as the depletion of glutathione, increased oxidative stress, mitochondrial dysfunction, and eventual liver necrosis [25]. These changes in liver morphology may have implications in hepatocarcinogenesis. Several animal studies have provided evidence for the carcinogenicity of paracetamol, especially in the liver [13]. For example, there is evidence that mice receiving high-dose of dietary paracetamol for 18 months had increased benign and malignant liver tumors at the end of the treatment period [26].

Alternatively, given that paracetamol use was associated with liver cancer risk among current users at relatively low number of prescription (e.g., 10-19), but not among past users even at high number of prescription (e.g., $\geq 40$ ), it is possible that reverse causation may partially explain the observed excess liver cancer risk with paracetamol use, because paracetamol may be used to treat mild-to-moderate pain in early stages of liver cancer, likely before diagnosis [27]. If this is the case, we would expect that changing the index date from 1 year to 2 years prior to the date of diagnosis might attenuate the association, but results were essentially unchanged in this sensitivity analysis (OR 1.20, 95\% CI 1.02-1.42 for everuse of paracetamol; Supplementary Table 4). Nevertheless, we cannot rule out the possibility that some current users already had pre-clinical liver cancer and used paracetamol to treat the pain, and this potential reverse causation warrants further investigation.

In our study, paracetamol was only associated with increased risk of liver cancer among individuals with BMI $<25 \mathrm{~kg} / \mathrm{m}^{2}$. The mechanisms underlying the interaction between paracetamol and BMI are unclear, but may involve differences in drug metabolism and clearance according to body size, as leaner individuals may tolerate paracetamol toxicity to a lesser extent than heavier individuals. In addition, it is likely that the etiology of liver cancer arising from excess adiposity may be different from that arising from other risk factors, such as HBV or HCV infection, in the absence of excess adiposity. It is also possible that this finding is due to chance, as we examined a number of potential effect modifiers and made multiple comparisons.

A major strength of this study is that the CPRD is a large, well-established, validated, longitudinal primary-care database, and is known for diagnostic accuracy of cancer 
outcomes and complete prescription pharmaceutical data. NSAID and paracetamol use was obtained from prescription data, which minimized information bias from self-report. Also, we attempted to reduce exposure misclassification by excluding cases and controls with less than two years of recorded medical history prior to their index date. However, this study also has a number of limitations. Exposure misclassification due to a lack of OTC data may have biased our estimates for both NSAIDs and paracetamol towards the null; however the bias is usually not large [22]. There is also potential for outcome misclassification, as a diagnosis of liver cancer was not confirmed by linkage to a cancer registry, although previous validation studies have shown that cancer diagnoses within the CPRD are reasonably complete [16]. In addition, the completeness of data for covariates may vary across patients and time [28]. Confounding by indication/contra-indication is also a concern. For example, patients at highest liver cancer risk (e.g., those with cirrhosis and portal hypertension with thrombocytopenia) may be advised to avoid NSAID use due to risk of gastrointestinal bleeding and renal failure [29], and these patients may be more likely to receive paracetamol rather than NSAIDs; however, results did not change materially when restricting the analyses to individuals without chronic liver disease (Supplementary Tables 1 and 2). Some participants may be using NSAIDs to treat pre-existing chronic inflammatory conditions, which may predispose them to higher risk of liver cancer, however data were not available on chronic inflammatory conditions as indications of NSAID use.

In conclusion, we observed no association between prescription NSAID use and liver cancer risk in the CPRD population, contrary to findings from previous studies based on self-report. This association should be further examined in future studies with both prescription and OTC medication data. In addition, we observed a slightly increased risk of liver cancer among ever-users of prescription paracetamol, but these results should be interpreted cautiously due to potential methodological limitations. As paracetamol is widely used for analgesia, its potential role in liver cancer development has strong public health relevance, and thus warrants further investigation.

\title{
Supplementary Material
}

Refer to Web version on PubMed Central for supplementary material.

\section{Acknowledgments}

This research was supported, in part, by the Intramural Research Program of the National Institutes of Health, National Cancer Institute. The authors thank Dr. Marie Bradley for her insightful comments, and Ms. Megan Braunlin for her help with the analyses.

\author{
Abbreviations \\ BMI body mass index \\ CI confidence interval \\ COX cyclooxygenase \\ CPRD Clinical Practice Research Datalink
}




$\begin{array}{ll}\text { GP } & \text { general practitioner } \\ \text { HBV } & \text { hepatitis B virus } \\ \text { HCC } & \text { hepatocellular carcinoma } \\ \text { HCV } & \text { hepatitis C virus } \\ \text { NSAID } & \text { Nonsteroidal anti-inflammatory drug } \\ \text { OR } & \text { odds ratio } \\ \text { OTC } & \text { over-the-counter }\end{array}$

\section{References}

1. Ferlay, J.; Soerjomataram, I.; Ervik, M.; Dikshit, R.; Eser, S.; Mathers, C.; Rebelo, M.; Parkin, DM.; Forman, D.; Bray, F. GLOBOCAN 2012 v1.0, Cancer Incidence and Mortality Worldwide: IARC CancerBase No. 11 [Internet]. 2013.

2. Ladep NG, Khan SA, Crossey MM, Thillainayagam AV, Taylor-Robinson SD, Toledano MB. Incidence and mortality of primary liver cancer in England and Wales: Changing patterns and ethnic variations. World J Gastroenterol. 2014; 20(6):1544. [PubMed: 24587630]

3. Altekruse SF, Henley SJ, Cucinelli JE, McGlynn KA. Changing Hepatocellular Carcinoma Incidence and Liver Cancer Mortality Rates in the United States. Am J Gastroenterol. 2014; 109(4): 542-553. [PubMed: 24513805]

4. El-Serag HB. Hepatocellular Carcinoma. N Engl J Med. 2011; 365(12):1118-1127. [PubMed: 21992124]

5. Altekruse SF, McGlynn KA, Reichman ME. Hepatocellular Carcinoma Incidence, Mortality, and Survival Trends in the United States From 1975 to 2005. J Clin Oncol. 2009; 27(9):1485-1491. [PubMed: 19224838]

6. Berasain C, Castillo J, Perugorria MJ, Latasa MU, Prieto J, Avila MA. Inflammation and Liver Cancer. Ann N Y Acad Sci. 2009; 1155(1):206-221. [PubMed: 19250206]

7. Leng J, Han C, Demetris AJ, Michalopoulos GK, Wu T. Cyclooxygenase-2 promotes hepatocellular carcinoma cell growth through AKT activation: Evidence for AKT inhibition in celecoxib-induced apoptosis. Hepatology. 2003; 38(3):756-768. [PubMed: 12939602]

8. Fodera D, D'Alessandro N, Cusimano A, Poma P, Notarbartolo M, Lampiasi N, Montalto G, Cervello M. Induction of Apoptosis and Inhibition of Cell Growth in Human Hepatocellular Carcinoma Cells by COX-2 Inhibitors. Ann N Y Acad Sci. 2004; 1028(1):440-449. [PubMed: 15650269]

9. Petrick JL, Sahasrabuddhe Vikrant V, Chan Andrew T, Alavanja Michael C, Beane-Freeman Laura E, Buring Julie E, Chen Jie, Chong Dawn Q, Freedman Neal D, Fuchs Charles S, Gaziano John Michael, Giovannucci Edward, Graubard Barry I, Hollenbeck Albert R, Hou Lifang, Jacobs Eric J, King Lindsay Y, Koshiol Jill, Lee I-Min, Linet Martha S, Palmer Julie R, Purdue Mark P, Rosenberg Lynn, Schairer Catherine, Sesso Howard D, Sigurdson Alice J, Wactawski-Wende Jean, ZeleniuchJacquotte Anne, Campbell Peter T, McGlynn KA. NSAID use and risk of hepatocellular carcinoma and intrahepatic cholangiocarcinoma: The Liver Cancer Pooling Project. Cancer Prev Res (Phila). 2015; 8(12):1156-1162. [PubMed: 26391917]

10. Sahasrabuddhe VV, Gunja MZ, Graubard BI, Trabert B, Schwartz LM, Park Y, Hollenbeck AR, Freedman ND, McGlynn KA. Nonsteroidal Anti-inflammatory Drug Use, Chronic Liver Disease, and Hepatocellular Carcinoma. J Natl Cancer Inst. 2012; 104(23):1808-1814. [PubMed: 23197492]

11. Chun LJ, Tong MJ, Busuttil RW, Hiatt JR. Acetaminophen hepatotoxicity and acute liver failure. Journal of clinical gastroenterology. 2009; 43(4):342-349. [PubMed: 19169150] 
12. Rossi S, Assis D, Awsare M, Brunner M, Skole K, Rai J, Andrel J, Herrine S, Reddy R, Navarro V. Use of Over-the-Counter Analgesics in Patients with Chronic Liver Disease. Drug-Safety. 2008; 31(3):261-270. [PubMed: 18302450]

13. Bergman K, Müller L, Teigen SW. The genotoxicity and carcinogenicity of paracetamol: a regulatory (re) view. Mutat Res. 1996; 349(2):263-288. [PubMed: 8600357]

14. Lawson DH, Sherman V, Hollowell J. The General Practice Research Database. Scientific and Ethical Advisory Group. QJM. 1998; 91(6):445-452. [PubMed: 9709463]

15. O'Neil M, Payne C, Read J. Read Codes Version 3: a user led terminology. Methods Inf Med. 1995; 34(1-2):187-192. [PubMed: 9082130]

16. Jick H, Jick SS, Derby LE. Validation of information recorded on general practitioner based computerised data resource in the United Kingdom. BMJ. 1991; 302(6779):766-768. [PubMed: 2021768]

17. Jick SS, Kaye JA, Vasilakis-Scaramozza C, Rodríguez LAG, Ruigómez A, Meier CR, Schlienger RG, Black C, Jick H. Validity of the general practice research database. Pharmacotherapy. 2003; 23(5):686-689. [PubMed: 12741446]

18. Jick H, Jick S, Derby LE, Vasilakis C, Myers MW, Meier CR. Calcium-channel blockers and risk of cancer. Lancet. 1997; 349(9051):525-528. [PubMed: 9048789]

19. McGlynn KA, Hagberg K, Chen J, Graubard BI, London WT, Jick S, Sahasrabuddhe VV. Statin Use and Risk for Primary Liver Cancer in the Clinical Practice Research Datalink. J Natl Cancer Inst. 2015; 107(4)

20. Rothwell PM, Price JF, Fowkes FGR, Zanchetti A, Roncaglioni MC, Tognoni G, Lee R, Belch JFF, Wilson M, Mehta Z, Meade TW. Short-term effects of daily aspirin on cancer incidence, mortality, and non-vascular death: analysis of the time course of risks and benefits in 51 randomised controlled trials. Lancet. 2012; 379(9826):1602-1612. [PubMed: 22440946]

21. Meier CR, Schmitz S, Jick H. Association Between Acetaminophen or Nonsteroidal Antiinflammatory Drugs and Risk of Developing Ovarian, Breast, or Colon Cancer. Pharmacotherapy. 2002; 22(3):303-309. [PubMed: 11898889]

22. Yood MU, Campbell UB, Rothman KJ, Jick SS, Lang J, Wells KE, Jick H, Johnson CC. Using prescription claims data for drugs available over-the-counter (OTC). Pharmacoepidemiol Drug Saf. 2007; 16(9):961-968. [PubMed: 17654746]

23. Barnett H, Burrill P, Iheanacho I. Don't use aspirin for primary prevention of cardiovascular disease. BMJ. 2010; 340:c1805. [PubMed: 20410163]

24. Friis S, Nielsen GL, Mellemkjær L, McLaughlin JK, Thulstrup AM, Blot WJ, Lipworth L, Vilstrup $\mathrm{H}$, Olsen JH. Cancer risk in persons receiving prescriptions for paracetamol: A Danish cohort study. Int J Cancer. 2002; 97(1):96-101. [PubMed: 11774249]

25. Hinson, J.; Roberts, D.; James, L. Mechanisms of Acetaminophen-Induced Liver Necrosis. In: Uetrecht, J., editor. Adverse Drug Reactions. Springer; Berlin Heidelberg: 2010. p. 369-405.

26. Flaks A, Flaks B. Induction of liver cell tumours in IF mice by paracetamol. Carcinogenesis. 1983; 4(4):363-368. [PubMed: 6839410]

27. Levy MH. Pharmacologic Treatment of Cancer Pain. N Eng J Med. 1996; 335(15):1124-1132.

28. Herrett E, Gallagher AM, Bhaskaran K, Forbes H, Mathur R, van Staa T, Smeeth L. Data Resource Profile: Clinical Practice Research Datalink (CPRD). Int J Epidemiol. 2015; 44(3):827-836. [PubMed: 26050254]

29. Singh S, Singh PP, Roberts LR, Sanchez W. Chemopreventive strategies in hepatocellular carcinoma. Nat Rev Gastroenterol Hepatol. 2014; 11(1):45-54. [PubMed: 23938452]

30. Royal Pharmaceutical Society of Great Britain. British national formulary. Pharmaceutical Press; 2012. 
- $\quad$ Prescription NSAID use is not associated with risk of primary liver cancer.

- $\quad$ Ever-use of paracetamol is associated with slightly higher liver cancer risk.

- $\quad$ Paracetamol-liver cancer association is stronger among leaner individuals. 


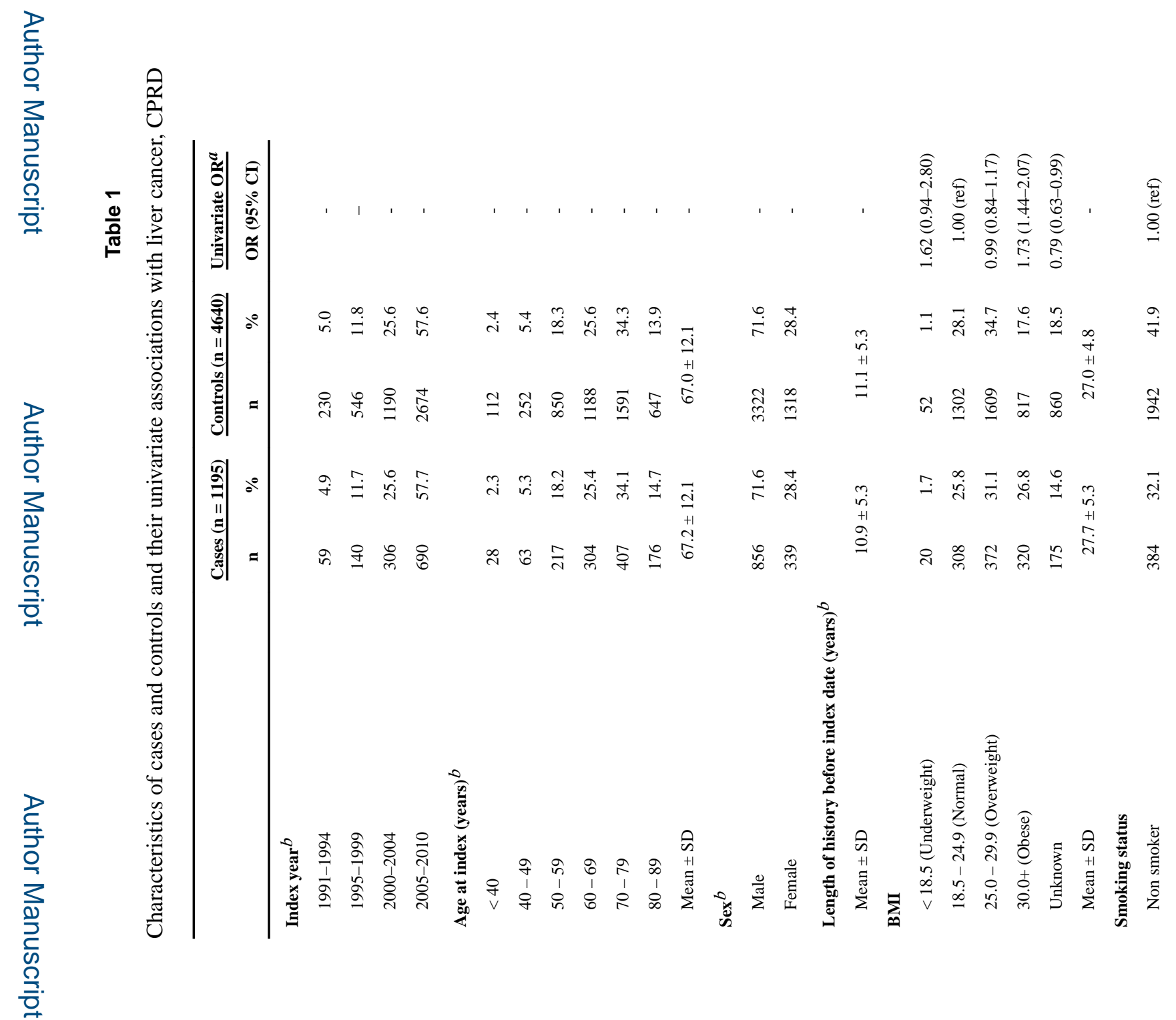




\section{을 \\ }

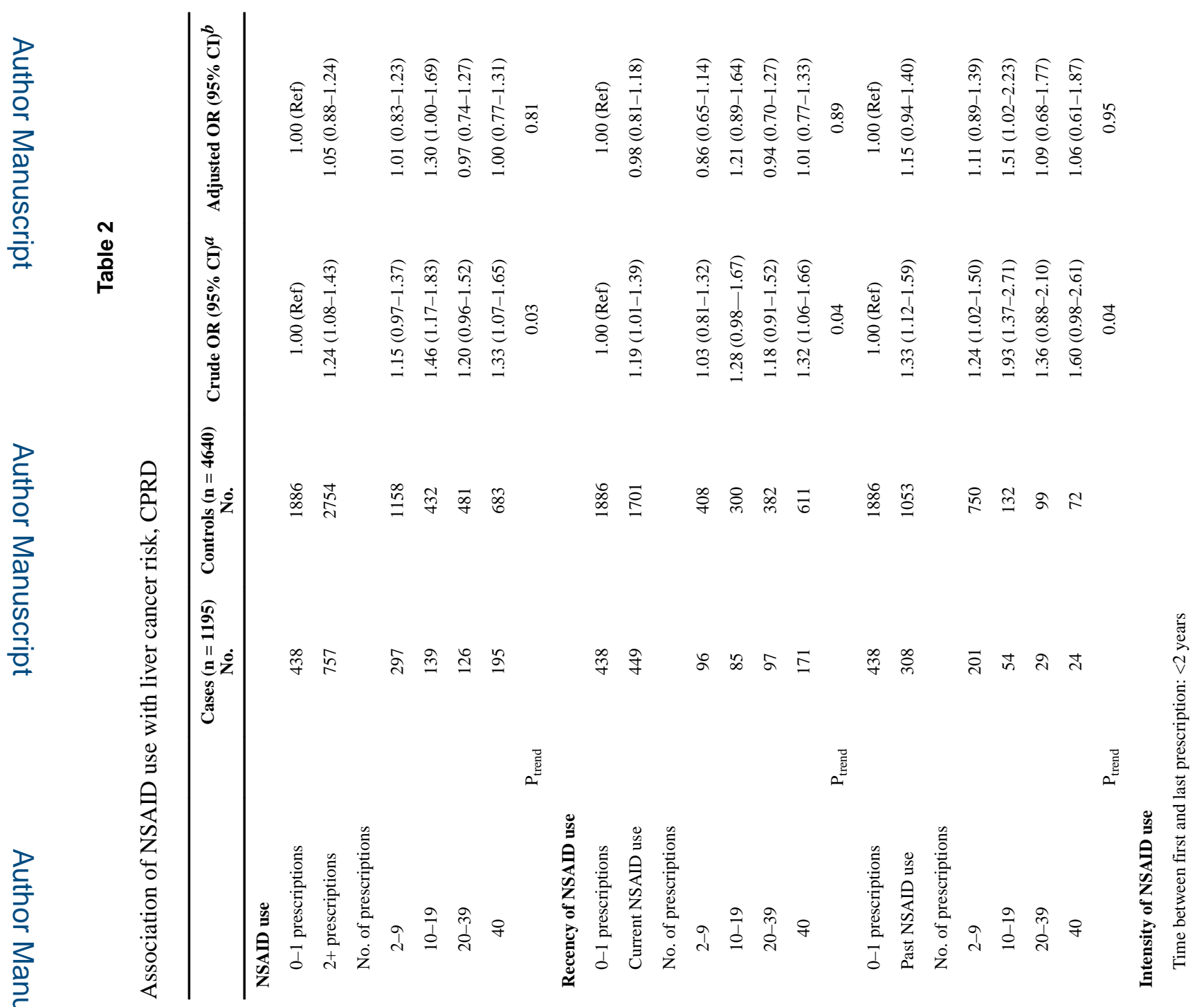


Table 3

Associations of NSAID subtypes with liver cancer risk, CPRD

\begin{tabular}{|c|c|c|c|c|}
\hline & $\begin{array}{c}\text { Cases }(n=1195) \\
\text { No. }\end{array}$ & $\begin{array}{c}\text { Controls }(n=4640) \\
\text { No. }\end{array}$ & Crude OR $(95 \% \mathrm{CI})^{a}$ & Adjusted OR $(95 \% \mathrm{CI})^{b}$ \\
\hline $0-1$ prescriptions of NSAIDs & 438 & 1886 & 1.00 (Ref) & 1.00 (Ref) \\
\hline Aspirin & 376 & 1294 & $1.35(1.11-1.65)$ & $1.11(0.86-1.44)$ \\
\hline COX-2 inhibitors (Coxibs) & 68 & 245 & $1.42(0.92-2.19)$ & $0.98(0.55-1.72)$ \\
\hline Rofecoxib & 35 & 119 & $1.13(0.64-2.02)$ & $0.84(0.41-1.71)$ \\
\hline Celecoxib & 34 & 103 & $2.11(1.12-3.97)$ & $1.61(0.74-3.53)$ \\
\hline Etoricoxib & 11 & 46 & $3.89(1.16-13.1)$ & $2.33(0.38-14.3)$ \\
\hline Propionic acid derivatives & 335 & 1238 & $1.18(0.97-1.43)$ & $0.97(0.76-1.24)$ \\
\hline Ibuprofen & 255 & 933 & $1.17(0.94-1.46)$ & $0.91(0.70-1.20)$ \\
\hline Naproxen & 82 & 307 & $1.10(0.78-1.57)$ & $0.97(0.63-1.49)$ \\
\hline Ketoprofen & 11 & 51 & $0.68(0.25-1.86)$ & $0.27(0.07-0.99)$ \\
\hline Tiaprofenic Acid & 8 & 22 & $1.55(0.39-6.21)$ & $1.63(0.31-8.48)$ \\
\hline Fenamic acid derivatives & 12 & 47 & $1.23(0.53-2.84)$ & $1.33(0.52-3.39)$ \\
\hline Mefenamic Acid & 12 & 46 & $1.23(0.53-2.84)$ & $1.34(0.52-3.42)$ \\
\hline Acetic acid derivatives & 328 & 1162 & $1.16(0.95-1.41)$ & $0.89(0.70-1.14)$ \\
\hline Diclofenac & 281 & 1015 & $1.13(0.91-1.39)$ & $0.83(0.64-1.09)$ \\
\hline Indomethacin & 47 & 120 & $1.30(0.80-2.11)$ & $1.08(0.60-1.92)$ \\
\hline Etodolac & 5 & 40 & $0.72(0.21-2.41)$ & $0.47(0.13-1.70)$ \\
\hline Nabumetone & 8 & 25 & $1.43(0.34-5.93)$ & $0.79(0.17-3.74)$ \\
\hline Enolic acid (Oxicam) derivatives & 44 & 183 & $1.31(0.80-2.13)$ & $0.97(0.53-1.77)$ \\
\hline Piroxicam & 16 & 72 & $0.77(0.35-1.70)$ & $0.57(0.23-1.43)$ \\
\hline Meloxicam & 28 & 105 & $1.74(0.94-3.21)$ & $1.31(0.62-2.75)$ \\
\hline
\end{tabular}

Abbreviations: $\mathrm{CI}=$ confidence interval; $\mathrm{COX}$, cyclooxygenase; $\mathrm{CPRD}=$ Clinical Practice Research Datalink; NSAID = nonsteroidal antiinflammatory drug; $\mathrm{OR}=$ odds ratio.

${ }^{a}$ Using conditional logistic regression to account for matching.

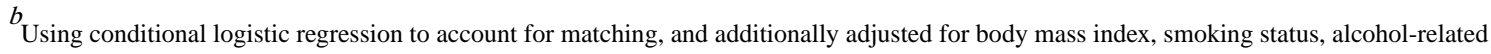
disorders, hepatitis B or C virus infection, diabetes, rare metabolic disorders, and use of paracetamol, antidiabetic medications, and statins. 


\section{을 \\ }

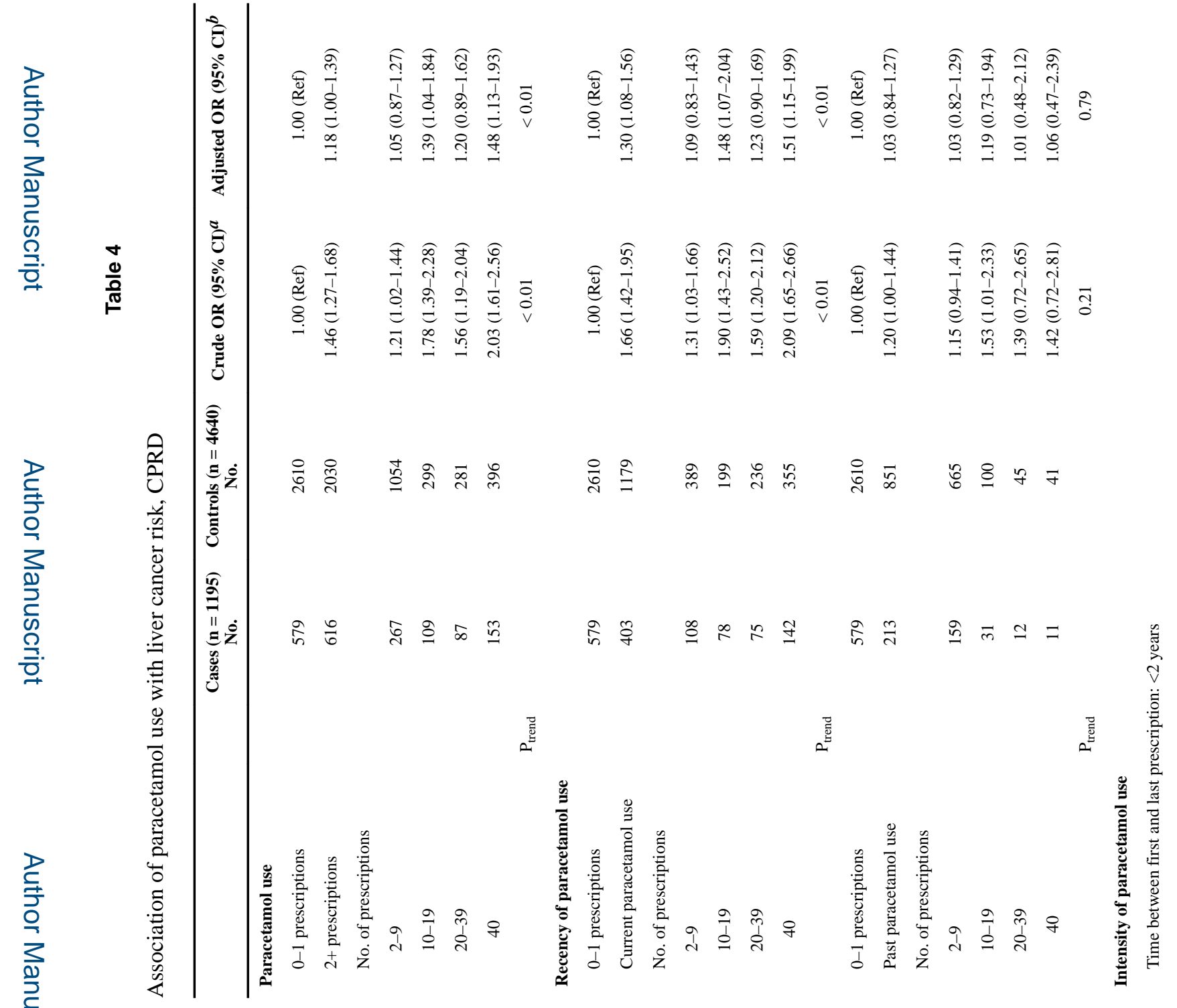


